Por Anna Gabriela Teixeira

- Raquel Souza Azevedo é coordenadora da Pós-Graduação em Enfermagem em Urgência, Emergência e Terapia Intensiva da Faculdade Unimed; Enfermeira Gerontóloga pela Sociedade Brasileira de Geriatria e Gerontologia e Consultora em Sistemas de Gestão da Saúde do Idoso. Mestre em Enfermagem pela UFMG, Especialista em Gerontologia pela FCMMG, Coordenadora de Enfermagem do Programa Mais Vida - SMSA / SES / HC, Preceptora da Residência Integrada Multiprofissional em Saúde do HC/UFMG e Membro Colaborador do Núcleo de Geriatria e Gerontologia da UFMG. 


\section{O PAPEL DA ENFERMAGEM EM UETI}

O papel de enfermeiros em urgência, emergência e terapia intensiva tem se tornado cada vez mais essencial no cenário da saúde. Com a explosão de casos de COVID e a lotação das UTIs e Prontos Socorros, estes profissionais estão sendo cada vez mais exigidos pelas instituições de saúde.

Diante deste cenário, convidamos a coordenadora da Pós-Graduação em Enfermagem em Urgência, Emergência e Terapia Intensiva, Raquel Souza Azevedo, para conversar sobre as funções deste profissional, qual o seu perfil e as exigências do mercado.

\section{Muitas vezes, em nosso dia a dia, nós nos referimos a "emergência" e "urgência" como sinônimos. Qual a diferença entre estes dois termos?}

Apesar de serem usados como sinônimos, eles realmente têm significados diferentes. De acordo com a definição do Ministério da Saúde, emergência é a constatação médica de condições de agravo à saúde que impliquem sofrimento intenso ou risco iminente de morte, exigindo, portanto, tratamento médico imediato. Já a urgências é a ocorrência imprevista de agravo à saúde como ou sem risco potencial a vida, cujo portador necessita de assistência médica imediata.

Esta distinção é muito importante na hora de triar os pacientes e definir as prioridades de atendimento, por exemplo.

\section{Qual a atuação de um enfermeiro em UETI?}

O enfermeiro é responsável por todo o processo de atendimento do paciente em situações de urgência e emergência e intervenções imediatas. Por isto é importante que o profissional conheça os procedimentos a serem realizados e tenha habilidades eficientes para o atendimento desde o atendimento pré-hospitalar até a recuperação e alta do paciente.

Outro ponto importante, são os conhecimentos gerenciais, o acolhimento com classificação de risco eficiente e atuar tanto em serviços móveis de urgência e Emergência (SAMU) e emergências pediátricas, quanto em hospitais. 
Sendo mais específica, a atuação no pronto atendimento engloba as seguintes ações:

- triagem: competência exclusiva do enfermeiro, é o primeiro atendimento aos pacientes, permitindo que o profissional tenha conhecimento do que deverá ser realizado, de acordo com a classificação de risco, permitindo que pacientes mais graves sejam priorizados imediatamente, porém sem dispensar nenhum paciente sem atendimento;

- prestação de cuidados ao paciente juntamente com o médico;

- preparação e administração de medicamentos;

- viabilização da execução de exames especiais, realizando a coleta;

- passagem de sondas nasogástricas, nasoenterais e vesicais em pacientes;

- realização de troca de traqueostomia e punção venosa com cateter;

- curativos complexos;

- preparação de instrumentos para intubação, aspiração, monitoramento cardíaco e desfibrilação, dando apoio a equipe médica diante da execução de diversos procedimentos;

- controle dos sinais vitais;

- evolução de paciente e anotação em prontuário.

O enfermeiro também é responsável por uma série de funções administrativas, como:

- estatística dos atendimentos prestados na unidade;

- liderança da equipe de enfermagem no atendimento à pacientes críticos e não críticos;

- coordenação das atividades dos profissionais que trabalham na recepção, limpeza e portaria;

- solução de problemas referentes ao atendimento médico ambulatorial;

- dimensionamento de pessoal e recursos materiais necessários;

- elaboração da escala diária e mensal da equipe de enfermagem;

- controle de materiais;

- verificação das necessidades de manutenção dos equipamentos do setor;

- pré-consulta, verificação dos sinais vitais e anotação da queixa atual do paciente; 
- preparação do material para punção subclávia e/ou dissecação de veia, bem como o apoio a equipe médica;

- evolução e anotação dos pacientes em observação na unidade.

Por fim, há a atuação em Unidade de Tratamento Intensivo. A UTI é um setor complexo e intenso, devendo o enfermeiro estar preparado para a qualquer momento, atender pacientes com alterações hemodinâmicas importantes, as quais requerem conhecimento específico e grande habilidade para tomar decisões e implementá-las em tempo hábil, para isto, o profissional deve estar capacitado a exercer atividades de maior complexidade, para as quais é necessária a autoconfiança e o conhecimento científico.

O papel do enfermeiro na UTI inclui obter a história do paciente, fazer exame físico, executar tratamento, aconselhando e ensinando a manutenção da saúde e orientando os enfermos para uma continuidade do tratamento. Coordenação e organização da equipe de enfermagem.

Um enfermeiro de UTI também precisa de ter conhecimento desde a administração e efeito das drogas até o funcionamento e adequação de aparelhos.

\section{Qual o perfil do profissional? Quais são as habilidades comportamentais necessárias para atuar neste mercado?}

O enfermeiro em UETI precisa desenvolver habilidades de gerenciamento (planejamento do cuidado, da previsão e da provisão de insumos); capacidade de liderança; supervisão; capacitação de sua equipe e habilidade de ensino.

Também é preciso ter boa capacidade de discernimento e raciocínio rápido, devido a imprevisibilidade do trabalho em emergências e urgências, o que também exige estabilidade emocional e capacidade de lidar com estresse.

Outro ponto importante é buscar a atualização constante, buscando sempre a melhoria do seu conhecimento científico e competência clínica.

Outro ponto importante é a empatia e o cuidado. O enfermeiro ocupa um importante papel nos momentos de fragilidade, dependência física e emocional do paciente. Além de apoiar a família 
e o paciente, ele também é o ponto de apoio para a equipe quer seja no que se refere à educação e preparo quer seja, na coordenação do serviço de enfermagem, atuando no limiar entre o humano e o tecnológico.

A tecnologia pode ser copiada; assim, o grande diferencial no mercado competitivo são as pessoas. Então o enfermeiro necessita ter conhecimento científico, prático e técnico, a fim de que possa tomar decisões rápidas e concretas, transmitindo segurança a toda equipe e principalmente diminuindo os riscos que ameaçam a vida do paciente.

\section{É preciso fazer prova de títulos para atuar ou basta ter a pós-graduação?}

Não é necessário fazer prova de título, por enquanto só a especialização é o suficiente. Mas caso o profissional tenha interesse em fazer a prova de títulos, a pós-graduação pode ser um diferencial. Como exemplo, trago o Edital ABENTI 2019:

Pré requisitos mínimos para inscrição: poderá se candidatar ao Título de Enfermeiro Especialista em Terapia Intensiva Adulto ou Pediátrica ou Neonatal, o enfermeiro que comprove por documentação legal pelo menos uma das condições abaixo:

1. no mínimo, 3 anos trabalhados como Enfermeiro em assistência ou gerenciamento ou ensino e pesquisa em Unidades de Terapia Intensiva (Adulto ou Pediátrica ou Neonatal);

2. inscrição no Sistema Cofen/ Corens e estar regular;

3. Certificado de Conclusão de Curso de Pós e Graduação Lato Sensu (Especialização) em Enfermagem em Terapia Intensiva (Adulto ou Pediátrica ou Neonatal.

\section{Como o enfermeiro pode se preparar para trabalhar nesta área?}

Uma pós-graduação em urgência e emergência é uma das grandes áreas de atuação do enfermeiro, em que é possível ampliar os horizontes frente à tomada de decisão em um momento crucial para o paciente.

A especialização em urgência e emergência na enfermagem é um dos cursos de maior procura nas instituições. Isso porque a temática desperta interesse dos enfermeiros para discriminar 
situações críticas e agir objetivamente e pelo contato com disciplinas relacionadas tanto à gestão desses serviços quanto à atuação clínica.

Na pós-graduação de Enfermagem em UETI da Faculdade Unimed, o aluno terá contato com temas como a sistematização da assistência em enfermagem, bioética e legislação, ferramentas para supervisão e avaliação dos funcionários, atendimento em urgência e emergência traumática e nas populações especiais (idosos, crianças, pessoas com limitações físicas, cognitivas etc.), atuação da enfermagem nos atendimentos de emergência relacionados ao transporte aéreo, aos termos técnicos e à condição mais complexa, que demanda pré, intra e pós- hospitalares. 